\title{
Erratum to: The Project Towards No Drug Abuse (TND) Dissemination Trial: Implementation Fidelity and Immediate Outcomes
}

Louise Ann Rohrbach • Melissa Gunning • Ping Sun • Steve Sussman

Published online: 15 October 2009

(C) Society for Prevention Research 2009

Erratum to: Prev Sci

DOI 10.1007/s11121-009-0151-Z

The original version of this article unfortunately contained a mistake. In the last paragraph of the Results section under Effects of Training Interventions on Implementation Fidelity, the last sentence should read as follows: The results indicated higher implementation fidelity in the IMP-SUPPORT condition classes (mean $=0.15, \mathrm{SD}=0.87$ ) relative to the REGULAR classes (mean $=-0.22, \mathrm{SD}=1.14 ; \mathrm{p}<0.05$ ).

The online version of the original article can be found at http://dx.doi. org/10.1007/s11121-009-0151-z.

L. A. Rohrbach $(\bowtie) \cdot$ M. Gunning $\cdot$ P. Sun $\cdot$ S. Sussman Department of Preventive Medicine, Institute for Health, Promotion and Disease Prevention Research,

University of Southern California,

1000 S. Fremont Ave., Unit \#8,

Alhambra, CA 91803, USA

e-mail: rohrbac@usc.edu 